\title{
Reformulación del principio de antropocentrismo ambiental
}

\section{The principle of environmental reformulation anthropocentrism}

\author{
Nelson Andrés Mantilla Oliveros \\ Abogado por la Universidad Santo Tomás Bucaramanga (Col.); especialista en Derecho Administrativo, Derecho \\ Ambiental por el Colegio Mayor de Nuestra Señora del Rosario (Col.); máster internacional (M.I.) de Derecho \\ Ambiental por el Instituto Internacional de Formación Ambiental de España; becario del Fondo Verde de España para \\ el programa de M.I. de Derecho Ambiental, Procuraduría General de la Nación. Dependencia: Procuraduría Delegada \\ para Asuntos Ambientales y Agrarios (Col.). \\ Correo electrónico: nelsonmantilla1@hotmail.com
}

\begin{abstract}
Resumen
De las principales declaraciones internacionales de principios ambientales han evolucionado los principios de desarrollo sostenible, de prevención, de precaución, el de contaminador-pagador, de soberanía de recursos naturales, de daño transfronterizo, entre otros; no obstante, a pesar de tales avances, existe un rezago sobre un principio que se encuentra claramente en esas declaraciones, el de antropocentrismo ambiental, concepto que ha sido mayormente malentendido al ser comprendido como un principio utilitario y de sobreexplotación de recursos naturales; no obstante, dicho principio en realidad contiene una relación estrecha con uno de los principios más importantes en nuestro ordenamiento jurídico, el de dignidad humana, debido a que si entendemos al antropocentrismo como una corriente que se ocupa de defender la supremacía o importancia del hombre por sobre las demás cosas, entonces toda vulneración y afectación que sufra la especie humana transgrede dicho mandato.
\end{abstract}

Palabras clave: Antropocentrismo, principio de derecho, jurisprudencia, dignidad humana, derecho blando, ecocentrismo.

\begin{abstract}
The main international declarations of environmental principles have evolved the principles of sustainable development, prevention, precaution, polluter pays , sovereignty of natural resources, transboundary harm , among others; However, despite such progress, there is a lag of a principle that is clearly in such statements, the environmental anthropocentrism, a concept that has been largely misunderstood to be understood as a utilitarian principle and overexploitation of natural resources; However, this principle actually contains a close relationship with one of the most important principles in our legal system, the human dignity because if we understand the anthropocentrism as a stream will defend the importance of male supremacy or above else, then any infringement and impairment suffered by the human species violates this mandate
\end{abstract}

Keywords: Anthropocentrism, rule of law, jurisprudence, human dignity, the right soft ecocentrism.

\section{Résumé}

Les principales déclarations internationales de principes environnementaux ont évolué les principes du développement durable, la prévention, de précaution, du pollueur-payeur, la souveraineté des ressources naturelles, les dommages transfrontières, entre autres; Cependant, malgré ces progrès, il y a un décalage sur un principe qui est clairement dans ces déclarations, l'anthropocentrisme environnementale, un concept qui a été en grande partie méconnue être comprise comme un principe utilitaire et la surexploitation des ressources naturelles; Cependant, ce principe a effectivement une relation étroite avec l'un des principes les plus importants dans notre système juridique, la dignité humaine, parce que si nous comprenons l'anthropocentrisme comme un flux qui gère maintenir la suprématie ou de l'importance de l'homme sur autres choses, toute l'humanité atteinte et l'implication des souffrances viole ce mandat.

Mots-clés: anthropocentrisme, primauté du droit, la jurisprudence, la dignité humaine, la écocentrisme douce droite.

Recibido: 15 de mayo de 2015; Aprobado: 13 de septiembre de 2015 



\section{Reformulación del principio de antropocentrismo ambiental}

Nelson Andrés Mantilla Oliveros

\section{INTRODUCCIÓN}

El derecho ambiental en la actualidad se entiende como una nueva rama del derecho que se encarga de regular los comportamientos del hombre con los recursos naturales renovables y los impactos que se generan de esa interacción. El aporte más importante para la evolución de esta rama del derecho proviene de las regulaciones internacionales que la comunidad concertó a inicios de los años setenta. Concretamente, nos referimos en primer lugar a la Conferencia de Naciones Unidas sobre el Medio Humano, realizada por la Organización de Naciones Unidas en Estocolmo, Suecia del 5 al 16 de junio de 1972.

Como resultado de dicha convocatoria, se publicó la declaración de principios sobre el medio humano que contiene 26 principios de marcada influencia ambiental con el fin de establecer un comienzo de regulación y concientización a nivel mundial de la importancia de conservar el medio. Más adelante, en consolidación a dicho propósito se realizó la Conferencia de las Naciones Unidas sobre Medio Ambiente y Desarrollo, celebrada en Río de Janeiro en Brasil del 3 al 14 de junio de 1992, de la cal se obtuvo como resultado -de entre otros- la declaración de principios de medio ambiente y desarrollo, manifiesto que contiene 27 principios que desarrollan muchos de los contenidos en la anterior declaración y otros nuevos. De las presentes declaraciones han evolucionado los principios de desarrollo sostenible, de prevención, de precaución, el de contaminador-pagador, de soberanía de recursos naturales, de 
daño transfronterizo, entre otros; a pesar de tales avances, existe un rezago sobre un principio que se encuentra claramente en tales declaraciones, el de antropocentrismo ambiental, concepto que ha sido mayormente malentendido al ser comprendido como un principio utilitario y de sobreexplotación de recursos naturales; no obstante, dicho principio en realidad contiene una relación estrecha con uno de los más importantes en nuestro ordenamiento jurídico, el de dignidad humana, debido a que si entendemos al antropocentrismo como una corriente que se ocupa de defender la supremacía o importancia del hombre por sobre las demás cosas, entonces toda vulneración y afectación que sufra la especie humana transgrede dicho mandato; siguiendo tal línea de pensamiento debemos entender que toda afectación grave al medio ambiente, ya sea de manera directa o indirecta, puede vulnerar al hombre y por ende, al principio que se estudia.

Así las cosas, se debe hacer un enfoque en una buena interpretación, o más bien, en una reformulación al principio del antropocentrismo, para que así se abandone la tesis malévola de que dicha corriente justifica un maltrato a los recursos naturales y al medio ambiente; para tal propósito, el estudio comienza con el acercamiento al valor del principio jurídico, seguido por un análisis de la corriente del antropocentrismo, las posturas que rechazan dicha corriente así como la propuesta de reformulación a luz de los conceptos de desarrollo sostenible, dignidad humana, el derecho de las generaciones futuras a subsistir, para así llegar a las conclusiones del trabajo.

\section{CONCEPTO DE PRINCIPIOS JURÍDICOS}

Como primera medida, abordaremos el concepto de principio de derecho; no obstante, sabemos que no es un tema tan pacífico como parece, debido a la gran proliferación de concepciones que ofrecen la doctrina y la jurisprudencia; retomando la definición de principios, encontramos en la doctrina jurídica varias aceptaciones sobre la aplicabilidad de los principios de derechos, los cuales varían dependiendo del ordenamiento jurídico donde se analicen; de acuerdo con lo anterior, por ejemplo, la aplicación pragmática de los principios se diferencia a gran escala en los ordenamiento jurídicos sometidos al common $l a w^{1}$ de los ordenamiento sometidos a civil law. El common law es el sistema jurídico desarrollado principalmente en Inglaterra, el cual se basa en un derecho consuetudinario y tiene como principal fuente a la jurisprudencia; por el contrario, el civil law es el sistema jurídico desarrollado en Europa continental, principalmente en Francia y España y se basa en un sistema estricto y positivo que tiene como principal fuente la ley; desde luego, debido a la influencia europea en Latinoamérica, este ha sido el sistema jurídico adoptado por la

"Destaca Cavana que el common law corresponde a una especial evolución del derecho inglés que no se ha detenido en su desarrollo prácticamente desde el siglo XII y ha llegado a nuestros días con un acervo de técnicas, experiencias y reglas no estrictas, esto en contraposición del derecho continental que fue objeto de profundas transformaciones propiciadas por los partidarios del derecho escrito" (Santofimio, p. 271). 
gran mayoría de los países suramericanos. Con referencia en lo anterior, para evitar cualquier tipo de confusión debe aclararse la diferencia existente entre principio y reglas normativas, pues mientras que los primeros son de contenido general, los segundos son normas escritas y concretas que regulan en sentido estricto cualquier tema, aun así, ambos son considerados normas jurídicas ${ }^{2}$.

Por supuesto, la jurisprudencia constitucional colombiana reconoce la presencia de principios en el ordenamiento jurídico sobre los cuales recae una función de fundamentación, integración e interpretación de esta, en los siguientes términos:

Los principios como lo reconoce la doctrina están llamados a cumplir en el sistema normativo los siguientes papeles primordiales: (i) Sirven de base y fundamento de todo el ordenamiento jurídico; (ii) actúan como directriz hermenéutica para la aplicación de las reglas jurídicas; y finalmente, (iii) en caso de insuficiencia normativa concreta y específica, se emplean como fuente integradora del derecho. En estos términos, es indiscutible que los principios cumplen una triple función de fundamento, interpretación e integración del orden jurídico. Se reconoce a los principios como fundamento, en la medida en que contribuyen a la organización deontológica de las distintas instituciones que dan soporte a la vida jurídica, esto es, fijan los criterios básicos o pilares estructurales de una determinada situación o relación social que goza de trascendencia o importancia para el derecho. En cuanto a su función como instrumento para la interpretación, esta Corporación ha dicho que los principios se convierten en guías hermenéuticas para descifrar el contenido normativo de las reglas jurídicas que al momento de su aplicación resulten oscuras, dudosas, imprecisas, indeterminadas o aun contradictorias en relación con otras normas de rango superior, incluyendo dentro de las mismas a los principios de naturaleza constitucional. Finalmente, los principios cumplen una función de integración, ya que asumen el rol de fuente formal del derecho ante la insuficiencia material de la ley para regular todas y cada una de las situaciones que se puedan presentar en el devenir social ${ }^{3}$.

En resumen, un principio de derecho, primero, es una norma o parámetro jurídico que está llamado a interpretar la norma jurídica escrita -regla jurídica- ${ }^{4}$, y que a su vez, no es una norma de contenido específico ni contempla escenarios fácticos concretos o enunciativos sino un postulado que, como tal, contiene valores

2 "En la teoría del derecho se reconocen a los principios y a las reglas como categorías de normas jurídicas. Ambas se suelen clasificar dentro de dicho concepto pues desde un punto de vista general (principio) o desde otro concreto y específico (regla) establecen aquello que es o debe ser. Así las cosas, tanto los principios como las reglas al tener vocación normativa se manifiestan en mandatos, permisiones o prohibiciones que delimitan y exigen un determinado comportamiento" (C. C. Sentencia C-818/05, M.P.: Rodrigo Escobar Gil).

3 Corte Constitucional, Sentencia C-818/05, M.P.: Rodrigo Escobar Gil.

4 Corte Constitucional, Sentencia C-818/05, M.P.: Rodrigo Escobar Gil. 
supremos de aplicación e interpretación del ordenamiento jurídico; de conformidad con lo anterior, el objeto principal del principio no es suplir la actividad del legislador pero si complementarla, rellenar el vacío jurídico que el legislador no puede y no debe regular en exceso. En aporte a dicha diferenciación, el profesor colombiano Santofimio Gamboa, defiende que:

el derecho, como lo señala García de Enterria, no puede agotarse en la simple ley, en el sentido del positivismo legalista: 'la tipificación de supuestos de hecho por el legislador no puede jamás agotar la variable y proteica riqueza de situaciones capaces de presentarse en la vida social, cuya evolución nada detiene' (s.f.).

De allí la existencia y razón de ser de los principios de derecho, en tanto que el legislador no puede abarcar la totalidad de escenarios con reglas específicas, mientras que los principios generales por su contenido general y abstracto, si pueden integrar todo el ordenamiento jurídico, y por ende, brindar de herramientas al operador para esclarecer problemas jurídicos donde no es palpable a simple vista una solución.

Por otra parte, debe hacerse claridad que los principios no suplen de ninguna manera la actividad legislador, mucho menos en un sistema jurídico como el colombiano, en el que la principal fuente de derecho y criterio de decisión es la ley $^{5}$, es decir, tal y como se explica en la providencia citada, los principios integran, interpretan y complementan el contenido de lo dicho por la principal fuente en nuestro ordenamiento, la ley, al igual que también son el principal instrumento para ponderar las colisiones entre derechos.

En complemento, se trae a colación la definición de principios del autor Lorenzetti, quien en opinión nuestra define de manera muy completa la esencia del principio:

El principio recepta los valores y ordena cumplirlos en la mejor medida posible. Por lo dicho, es una norma jurídica prima facie, es decir, inacabada, no contiene un supuesto de hecho ni es determinado, sino por el contrario, es abierto. El principio es un mandato, ordena hacer algo, pero no lo dice de modo preciso, ni en relación a un supuesto de hecho, como lo hace la regla, sino en la mejor medida posible. Por ello es un mandato de optimización, ya que ordena la realización de un valor de la manera más plena posible (s.f.).

La anterior valoración jurídica hecha por el autor citado nos contrae obligatoriamente al análisis y jerarquía del sistema de fuentes del derecho, al establecer que el principio recepta y hace una abstracción sustancial del valor y a su vez, la regla jurídica -norma- debe desarrollar los postulados del principio, de conformidad con la jerarquía normativa del sistema de fuentes formales del derecho; no obstante, dicho análisis de fuentes, jerarquía y aplicación por complejo y controversial que sea,

“Artículo 230. Los jueces, en sus providencias, solo están sometidos al imperio de la ley. La equidad, la jurisprudencia, los principios generales del derecho y la doctrina son criterios auxiliares de la actividad judicial" (Constitución Política de Colombia). 
no es tema del presente escrito; empero, para el desarrollo del presente trabajo no podía pasar desapercibido en el desarrollo de este trabajo.

Para terminar con el presente capítulo, concluimos para efectos prácticos que el principio es una norma jurídica general y abstracta que sirve de base para la construcción de las reglas jurídicas, y que además, es una fuente formal del derecho y tiene como objeto fundamentar, integrar e interpretar el ordenamiento jurídico.

\section{EL ANTROPOCENTRISMO}

En aras de ilustrar el tema, debemos hacer un estudio de las corrientes filosóficas que se han encargado de estudiar la interacción del hombre con los recursos naturales y la importancia de estos; en concreto, nos enfocaremos en las dos corrientes más relevantes y que exponen posturas contrarias en aras de elaborar una ilustración del presente principio bajo el enfoque del autor. En efecto, las corrientes filosóficas que se han debatido en los últimos siglos son el ecocentrismo y el antropocentrismo; analicemos las raíces -literales- de los términos:

- $\quad$ Antro $=$ hombre; centrismo $=$ centro.

- $\quad$ Eco centrismo: Eco = casa, morada o ámbito vital; centrismo = centro.

Como corolario de lo anterior, tenemos entonces por un lado una corriente donde se afirma que el hombre es el centro del cosmos y, por lo tanto, la interacción entre el hombre y los recursos naturales siempre debe favorecer al hombre o rondar en torno a él; por el otro lado, tenemos una corriente más conservacionista que nos dice que el ambiente es el centro del cosmos y, por tanto, el hombre es solo un ingrediente dentro de la gran interacción de la vida. Dicho lo anterior, debemos agregar que la corriente antropocentrista ha predominado a lo largo del tiempo, puesto que es una corriente que comparte la tesis rígida y civilista de que los recursos naturales están a disposición del hombre sin prevención alguna; además, la conciencia ambiental y las corrientes ecocentristas o ecológicas, podemos decirlo sin ningún temor, son corrientes novísimas que tienen inicios a partir de los años 1900, mientras que el antropocentrismo viene imperando desde antes de la edad media ${ }^{6}$.

Ahora, políticamente hablando, podemos hacer un paralelo de las declaraciones internacionales referenciadas anteriormente, y encontraremos que a pesar de tener varias similitudes, la declaración de principios de 1992 tiene un enfoque más ecocéntrico, respecto a la de 1970, sin dejar de ser también una declaración antropocentrista; en concreto, la declaración de Naciones Unidas del Medio Humano de 1970 se proclama de la siguiente forma:

El hombre es a la vez obra y artífice del medio que lo rodea, el cual le da el sustento material y le brinda la oportunidad de desarrollarse intelectual, moral, social y espiritualmente. En la larga y tortuosa evolución de la raza

6 Periodo de tiempo comprendido entre los años 476-1492. 
humana en este planeta se ha llegado a una etapa en que, gracias a la rápida aceleración de la ciencia y la tecnología, el hombre ha adquirido el poder de transformar, de innumerables maneras y en una escala sin precedentes, cuanto lo rodea. Los dos aspectos del medio humano, el natural y el artificial, son esenciales para el bienestar del hombre y para el goce de los derechos humanos fundamentales, incluso el derecho a la vida misma.

Ahora, no estamos acusando a la presente declaración de ser un instrumento en contra del ambiente; no, lo único que ponemos de presente es que la declaración comparte la corriente antropocentrista toda vez que su primera frase es una proclama que ubica al hombre en el centro del universo; es más, el punto de vista que pretendemos exponer y que consideramos como un principio del derecho ambiental es el antropocentrismo bien entendido, y por tal razón se propone con este escrito reformular el entendimiento que se tiene de dicho principio a la luz del principio de dignidad humana; en otras palabras, queremos desvirtuar las afirmaciones perversas que pretenden decir que el antropocentrismo es una justificación jurídica y social para devorar el ambiente.

Más adelante, la declaración de Río de Janeiro, a pesar de seguir dentro del antropocentrismo, incluye la variable ambiental bajo el esquema del principio de desarrollo sostenible; a saber, la declaración hace la siguiente proclama como primer principio de dicha carta:

\section{Principio 1}

Los seres humanos constituyen el centro de las preocupaciones relacionadas con el desarrollo sostenible. Tienen derecho a una vida saludable y productiva en armonía con la naturaleza.

Claramente, la declaración vuelve y retoma lo dicho en 1970 en ubicar a los seres humanos como el centro de la proclama; no obstante, lo hace con sujeción al principio del desarrollo sostenible y en especial, a su variable ambiental.

Teniendo en cuenta tales declaraciones, podríamos pensar aunque muchos no compartan tal afirmación, que las principales declaraciones internacionales de contenido ambiental tienen una gran influencia antropocéntrica, situación que ha permeado en las regulaciones de cada país y por lo tanto se hayan adoptado tales discursos; sin embargo, lo que queremos argumentar es que tal circunstancia no es del todo gravosa para el ambiente, pues el antropocentrismo aunque tiene una visión limitada del cosmos, no es del todo un mandato o corriente que permita la degradación desmedida del medio ambiente.

Cabe anotar, que existe una discusión jurídica sobre la obligatoriedad de estos instrumentos jurídicos de derecho internacional -declaraciones de principios-, puesto que los mismos no son tratados internacionales y que por esta razón son simples documentos sin validez jurídica; sin embargo, debe aclararse, la discusión sobre validez y existencia no puede llegar a desconocer la proclamación de un órgano 
internacional que por consenso ha hecho una declaración de principios; es decir, pretender desconocer de tajo la existencia y la validez de estos instrumentos se contrapone con el principio de voluntad del órgano que proclamó el documento y con la misma función y objetivo de las organizaciones internacionales.

En concepto nuestro, hay que diferenciar la existencia y validez de las declaraciones mencionadas anteriormente, en contraste con los conceptos de obligatoriedad y fuerza jurídica de sanción de los presentes documentos. En esos términos, la Corte Constitucional ha establecido que a pesar de no tener fuerza vinculante, los instrumentos jurídicos, tales como declaraciones de principios, que han sido denominados por el sistema anglosajón soft law por su significado en inglés -derecho blando-, tienen un objetivo jurídico, el cual es la virtud de interpretación jurídica de instrumentos jurídicos de hard law, en concreto:

Además de los tratados, pactos y convenciones existen los instrumentos internacionales de derechos humanos que hacen parte del así denominado en la doctrina anglosajona soft law. Se trata de declaraciones o principios elaborados por expertos, relatores o cuerpos especializados que tiene un valor importante en la medida en que constituyen un desarrollo doctrinal sobre el alcance de determinados tratados de derechos humanos, sin embargo no tiene un carácter vinculante, a diferencia de los tratados. Esta Corporación ha sostenido que ciertos documentos que hacen parte del soft law tienen utilidad interpretativa de los tratados internacionales de derechos humanos y han sido empleados para establecer el alcance de las obligaciones del Estado colombiano en la materia?

En resumen, la existencia, validez y objetivo jurídico de los instrumentos de derecho internacional de contenido blando no puede desconocerse, puesto que sería tanto como decir que tal instrumento no existe; por consiguiente, sería sustraer de total relevancia el hecho de que la comunidad internacional bajo sus delegados plenipotenciarios y órganos adjuntos se hayan reunido para adoptar por consenso una declaración de principios; sobre tal afirmación, podría pensarse que entonces dichas cumbres serían una pérdida de tiempo y de recursos, pues si en realidad las declaraciones no tienen ninguna importancia y relevancia jurídica, entonces cual es el sentido de hacer la proclama.

Eso sí, debe precisarse que estos no tienen un carácter vinculante e impositivo sancionatorio; es decir, bajo tales principios o incumplimiento de estos instrumentos jurídicos no se puede sancionar a un Estado, toda vez que son instrumentos jurídicos de derecho blando y en su contenido no se expresan obligaciones concretas. Empero, cabe aclarar, muchos de los tratados adoptados por la comunidad internacional y que hacen parte del derecho duro -Hard Law - de los ordenamientos jurídicos, han sido diseñados para que no pasen de ser unas declaraciones contentivas de discursos

7 Corte Constitucional, Sentencia C-257 de 2008, M.P.: Clara Inés Vargas. 
políticos inaplicables; en otras palabras, a pesar de tener fuerza vinculante, sus disposiciones orgánicas y dogmáticas no tienen la capacidad de ser instrumentos aplicables; por ejemplo, la convención marco de las Naciones Unidas para el Cambio Climático no tuvo mayor fuerza vinculante - concreta- sino hasta que se pactó su Protocolo Adicional -Kioto-y más sin embargo, varios países eludieron su responsabilidad al hacerse parte del convenio pero no del Protocolo; por consiguiente, vemos cómo en algunas ocasiones las normas "jurídicamente vinculantes" no pasan de ser buenas intenciones, argumento que refuerza la postura de reconocer la existencia de las declaraciones, su valor y objeto jurídico.

Al margen de la discusión, la declaración de principios de Río Janeiro 1992, enunciada anteriormente, no ha sido integrada mediante ley aprobatoria de tratados internacionales; de hecho, al ser una declaración de principios no tiene el mismo tratamiento que por ejemplo, el convenio marco de las Naciones Unidas para el cambio climático, o para la protección de la diversidad biológica; no obstante, nuestro ordenamiento colombiano, en particular, la Ley 99 de 1993 hizo una introducción sui generis de los principios contenidos en la declaración de Río de 1992. En efecto, tildamos de sui generis la precedida inclusión toda vez que mediante el artículo primero de la Ley 99 de 1993 se hace una inclusión atípica de todo el instrumento jurídico ${ }^{8}$.

Aunque desde un punto de vista muy tradicionalista se podría criticar dicha inclusión, nos remitimos, y compartimos, al pronunciamiento de la Corte Constitucional mediante la cual se declara la exequibilidad de la anterior inclusión normativa donde se diferencia claramente entre un tratado internacional o instrumento jurídico internacional de contenido duro, de una declaración de principios de un órgano internacional:

Desde luego, en este caso los principios a los que se refiere la disposición acusada no son constitucionales o generales, ni fundamentadores del ordenamiento jurídico político, como podría entenderse inicialmente y como lo quiere entender el demandante al equipararlos al preámbulo de la Constitución; ni sirven para condicionar toda la organización del Estado, ni se predican de todo el ordenamiento jurídico, sino que operan con la capacidad de ser orientadores de la conducta de los funcionarios encargados de adelantar el cumplimiento de las restantes partes de la ley que establece. Se hace necesario reconocer la existencia de ordenamientos jurídicos parciales que funcionan de modo relativamente autónomo, dentro de la unidad y plenitud del sistema jurídico al que pertenecen; estas pautas de conducta también condicionan las actividades de los jueces en funciones de

8 Artículo $1^{\circ}$. Principios Generales Ambientales. La política ambiental colombiana seguirá los siguientes principios generales:

1. El proceso de desarrollo económico y social del país se orientará según los principios universales y del desarrollo sostenible contenidos en la Declaración de Río de Janeiro de junio de 1992 sobre Medio Ambiente y Desarrollo. 
aplicación de la ley y de su interpretación, y en dicha medida son utilizados por el derecho contemporáneo, para abrir las capacidades de los operadores del derecho a soluciones que incorporan fundamentos de racionalidad jurídica y de razonabilidad práctica.

Se observa que esta modalidad no es nueva dentro de los Estados de derecho, y que desde los albores de la revolución liberal se acude a la incorporación de los principios contenidos en declaraciones universales de derechos y de valores, como la Declaración Universal de los Derechos del Hombre y del Ciudadano, sin que por su incorporación por vía de principio de interpretación de la ley o de pautas de conductas legalmente reconocidas dentro de las estructuras de los ordenamientos jurídicos, o de referencias de carácter normativo y de vigor jurídico, se les esté incorporando como si fuesen tratados internacionales o convenciones o cualquiera otro instrumento de dicha índole.

En este caso se encuentra que la declaración a la que se hace referencia no es un instrumento internacional, ni es un documento que está abierto a la adhesión de los Estados o de los organismos internacionales o supranacionales, con el carácter de un instrumento internacional con fuerza vinculante; es una declaración producida por la Conferencia de las Naciones Unidas sobre el Medio Ambiente y el Desarrollo, reunida en Río de Janeiro del 3 al 14 de junio de 1992, en la que se proclaman los mencionados principios.

La Corte considera, ante esta situación, que no es del caso aceptar la inconstitucionalidad solicitada. Por el contrario, procederá a declarar su exequibilidad ya que ella encuentra fundamento no sólo en el Preámbulo de la Constitución sino en los artículos 1o. y 2o., en los que se establecen los fines del Estado y los principios fundamentales de la organización jurídico política de la Nación, dentro de los que se encuentran los de la prevalencia del interés general, la solidaridad de las personas que la integran y el propósito de asegurar la convivencia pacífica y un orden justo. Así mismo es preciso considerar que el artículo 339 de la C.P. condiciona la elaboración de la parte general del Plan Nacional de Desarrollo al señalamiento de las estrategias y orientaciones generales de la política ambiental que será adoptada por el Gobierno.

De igual modo, debe tenerse en cuenta que las autoridades de la República están instituidas para asegurar el cumplimiento de los deberes sociales del Estado y de los particulares; en este sentido es claro que en dichos principios, cuyo reconocimiento legal se impugna por la demanda, se establecen las mencionadas pautas que encuentran en la defensa del ambiente sano uno de los derechos colectivos que deben ser protegidos por el Estado según la Carta Política de 1991, como quiera que en el artículo 80 de aquella, se 
observa que es deber del Estado planificar el manejo y aprovechamiento de los recursos naturales para garantizar su desarrollo sostenible, su conservación, restauración o sustitución. Además, el mencionado artículo de la Constitución advierte que el Estado debe prevenir y controlar los factores de deterioro ambiental y cooperar con otras naciones en la protección de los ecosistemas ubicadas en las zonas fronterizas 9 .

Debemos aclarar que la Corte en principio hace la afirmación de que no es instrumento jurídico internacional; no obstante, renglones abajo, hace la claridad que a lo que no puede homologarse es a un instrumento jurídico vinculante, es decir, como un instrumento hard law; por consiguiente, a pesar de que no puede reconocerse una fuerza vinculante, no es menos cierto que pueda desconocerse su función interpretativa en términos que la misma Corte ha establecido en otros pronunciamientos, uno de ellos citado en el presente escrito; de otro lado, tales principios al ser incorporados en la Ley 99 de 1993 por medio de la cual se organiza el Sistema Ambiental Nacional y se dictan otras disposiciones, constituyen las herramientas interpretativas para cumplir los términos legales que se establecen en esta y que se deberán aplicar a nivel nacional; es decir, dichos principios no solo rigen la interpretación de los tratados y convenciones incorporados en nuestro ordenamiento, sino que también orientan la política ambiental de nuestro país al haber sido incorporados mediante la Ley 99 de 1993, tal y como lo expone la providencia citada.

\section{RECHAZO DEL ANTROPOCENTRISMO}

En primer término, hacemos referencia al rechazo por parte de la doctrina constitucional sobre la corriente antropocentrista, pues considera que dicha corriente es el germen de la autodestrucción, al ser un enfoque egoísta de la especie humana:

...En conclusión, la relación humana con el medio ambiente no puede continuar siendo antropocentrista, dicho esquema de correlación es el germen de la autodestrucción, por tanto se torna inaplazable y necesario entender que todo está holísticamente enlazado y que la protección, va más allá de la mera normativa y su cumplimiento, puesto que lo que está en juego no es solo la subsistencia de la especie humana, sino la vida como un todo ${ }^{10}$.

En igual sentido, la Corte en otrora se pronuncia de la siguiente manera:

Si bien es cierto, como lo ha establecido la jurisprudencia, que existe una estrecha relación entre los derechos a la salud y a la vida con el derecho al medio ambiente, la protección de la naturaleza no sólo debe hacerse en

9 Corte Constitucional, Sentencia C-528 de 1994, M.P.: Fabio Morón Díaz.

10 Corte Constitucional, Sentencia T 129 de 2011, M.P.: Jorge Iván Palacio Palacio. 
aras de proteger al ser humano. El medio ambiente no debe ser concebido solamente desde una perspectiva antropocéntrica, entendiendo que el único fin de preservación es que en un futuro la naturaleza tenga alguna utilidad para el ser humano y no sea aliciente en el progreso de la humanidad, sino que la postura frente a éste bien debe ser de respeto y de cuidado. Teniendo en cuenta que debe haber un desarrollo armónico en donde el actuar de los seres humanos en relación al medio ambiente debe responder a la visión en donde los demás integrantes del medio ambiente son entes dignos que no se encuentran a disposición absoluta e ilimitada del ser humano. De tal forma que debe ser vista y entendida bajo el supuesto de que el ser humano es un elemento más de la naturaleza y no un superior que tiene a su disposición el medio ambiente ${ }^{11}$.

Como se puede observar en ambos pronunciamientos, la Corte Constitucional en buena forma rechaza una visión antropocéntrica egoísta, donde la sola calidad de ser humano imparte cierta superioridad sobre el resto de la naturaleza, concepción que deviene de una mirada utilitaria y retrograda; no obstante, dicha visión bajo otro entendimiento puede ser de gran aporte para el cuidado del medio ambiente y la convivencia armónica del ser humano con los recursos naturales, paradigma que en vísperas de la evolución del Estado social de derecho, la Constitución de 1991 y el ordenamiento convencional debe ser reformulado.

Sobre este particular, debe diferenciarse la aplicación del principio de antropocentrismo ambiental, pues, por un lado, una cosa es que se entienda de manera egoísta en relación a que el hombre puede sobreexplotar los recursos naturales sin ningún tipo de limitación y prevención bajo el argumento de que el hombre es el centro del cosmos, y otra muy diferente es comprender que el ordenamiento jurídico colombiano le reconoce a la persona unos derechos constitucionales, dentro de esos, el derecho a la vida y a la dignidad humana, y que toda afectación al medio ambiente de alguna manera afecta a la especie, al ser el receptor principal de los bienes y servicios ambientales, pues como lo menciona Molina Roa al entender al medio ambiente como el sustrato necesario para la vida (Roa, 2014). Cabe agregar que, desde el punto de vista jurídico, ha de recordarse que mayoritariamente los ordenamientos jurídicos solo confieren derechos a las personas, a diferencia, por ejemplo de países como Ecuador o Bolivia, donde se han reconocido derechos al medio ambiente $^{12}$, o de otro lado, y de manera muy reciente en nuestro ordenamiento, en el que se reconocieron derechos a los animales con la expedición del nuevo Plan Nacional de Desarrollo $^{13}$; eso sí, bajo la supremacía de los derechos reconocidos a los seres humanos.

11 Corte Constitucional, Sentencia T 608 de 2011, M.P.: Juan Carlos Henao Pérez.

12 Al respecto léase Derechos de la naturaleza, historia y tendencia actuales de Javier Alfredo Molina.

13 Artículo $248^{\circ}$. Política pública de defensa de los derechos de los animales y protección animal El Gobierno nacional promoverá políticas públicas y acciones gubernamentales en las cuales 
Hechas las anteriores anotaciones, pasamos a exponer el enfoque por medio del cual debe reformularse el antropocentrismo, o mejor aún, el principio de antropocentrismo ambiental, que como quedó evidenciado, se encuentra en el principio número uno de la declaración de Río, incorporado a nuestro ordenamiento mediante el artículo 1 de la Ley 99 de 1993, y de esta forma contrarrestar el hecho real de que se encuentra en nuestro ordenamiento jurídico y que bajo una interpretación nociva con el medio, se podría llegar a una consecuencia trágica en la gestión ambiental y la defensa del medio.

\section{REFORMULACIÓN DEL PRINCIPIO}

Para tal propósito, debemos remitirnos a un pronunciamiento de la Honorable Corte Constitucional donde se hace referencia al derecho a gozar de un ambiente sano y el medio ambiente en sí mismo:

En la Constitución de 1991 la defensa de los recursos naturales y medio ambiente sano es uno de sus principales objetivos, como quiera que el riesgo al cual nos enfrentamos no es propiamente el de la destrucción del planeta sino el de la vida como la conocemos. El planeta vivirá con esta o con otra biosfera dentro del pequeño paréntesis biológico que representa la vida humana en su existencia de millones de años, mientras que con nuestra estulticia sí se destruye la biosfera que ha permitido nacer y desarrollarse a nuestra especie estamos condenándonos a la pérdida de nuestra calidad de vida, la de nuestros descendientes y eventualmente a la desaparición de la especie humana $^{14}$.

Concretamente, queremos hacer referencia a la consecuencia trágica que expone la doctrina constitucional, la desaparición de la especie humana; de lo anterior, haremos un análisis para llegar al principio de antropocentrismo ambiental, como lo entendemos. Hoy en día, se quieren confundir, casi de aposta, los conceptos de antropocentrismo con el de capitalismo salvaje y explotación desmedida e insostenible de recursos naturales, asimilación que no compartimos, toda vez que sostiene que el antropocentrismo es la justificación o excusa humana para una explotación

se fomenten, promulguen y difundan los derechos de los animales y la protección animal. Para tal efecto, en coordinación con las organizaciones sociales de defensa de los animales, diseñará una política en la que se establecerán los conceptos, competencias institucionales, condiciones, aspectos, limitaciones y especificaciones sobre el cuidado animal, en cuanto a la reproducción, tenencia, adopción, producción, distribución y comercialización de animales domésticos no aptos para reproducirse. Las entidades territoriales y descentralizadas del Estado se encargarán de vigilar, controlar y fomentar el respeto por los animales y su integridad física y anímica. Adicionalmente, las organizaciones sociales de defensa de los animales participarán de manera coordinada con las entidades nacionales y territoriales para la difusión de las políticas a que se refiere el presente artículo. Parágrafo. Se mantendrán las excepciones contempladas en el artículo 7 de la Ley 84 de 1989.

14 Corte Constitucional, Sentencia C-339 de 2002, M.P.: Jaime Araujo Rentería. 
desmedida de los recursos del ambiente; sin embargo, recalcamos, una cosa es que el antropocentrismo sea visto como una excusa capitalista-devoradora, y otra muy diferente es que se identifique de manera correcta con el principio del desarrollo sustentable y de dignidad humana, fusión conceptual que nos crea el principio de antropocentrismo ambiental.

Así pues, si algún ordenamiento se identifica con el antropocentrismo, es decir, que el hombre es el centro de las preocupaciones, entonces cabe hacer la siguiente afirmación y de esta forma concluir de manera preliminar lo que se sustenta en el presente trabajo: no hay nada más antropocentrista que cuidar el ambiente en aras de garantizar la vida y la especie humana; o dicho de otra forma, en términos más jurídicos, la garantización de principios constitucionales como el de dignidad, que dicho sea de paso, es el principio estructural del estado social de derecho, se puede lograr gracias y a través de la protección de los recursos naturales y el medio ambiente; en consecuencia, una vía jurídica para garantizar la dignidad humana es el cuidado del ambiente y de los recursos naturales, toda vez que como lo dice la Corte Constitucional, cualquier deterioro grave en contra de la naturaleza, no solo pone en peligro el ambiente mismo sino a toda la especie humana. El anterior cuestionamiento nos lleva al extremo de pensar si el hombre podría vivir dignamente en un espacio contaminado; consideramos que no, pues no solo se afectaría la dignidad de la persona, sino su propio derecho a la vida, que por condiciones insalubres podría estar en peligro.

Otro argumento que nos sirve para reforzar nuestra propuesta y que hasta el momento no ha sido referido en el presente estudio, es la nueva importancia que cobran las generaciones futuras a la luz del principio del desarrollo sostenible, pues la guarda del ambiente en condiciones óptimas para la vida no solo garantiza sus derechos -los de las generaciones futuras-, sino la prolongación de la vida en la tierra ${ }^{15}$; así las cosas, visto de alguna forma y así sea un enfoque egoísta, los seres humanos deben tener dentro del centro de sus preocupaciones la supervivencia de la raza humana (antropocentrismo), y para ello debemos garantizar el medio natural, entonces ese debe ser el propósito fundamental de los Estados y así debe ser visto el antropocentrismo, mas no como una utilización desmedida de los recursos naturales renovables y los no renovables.

En esa virtud, así como el antropocentrismo puede interpretarse como la justificación legal para sobreponer un modelo impactante dizque en virtud de la primacía humana sobre el medio natural, también podemos y debemos interpretarlo como el sustento principal para proteger el medio ambiente, puesto que no habrá nunca nadie más interesado en la protección del medio ambiente -su medio de vida-

15 "Es en todo caso ostensible que la protección del entorno natural es una indeclinable obligación general de la humanidad de hoy, para preservar inalienables derechos de las generaciones futuras, estando en juego nada menos que la prolongación de la vida en el planeta Tierra" (Corte Constitucional, Sentencia T 724 de 2001, M.P.: Nilson Pinilla Pinilla). 
sino el hombre, pues hay algo que nunca debe perderse de vista, y por obvio que sea debemos recordarlo, la naturaleza es anterior a la raza humana, es más, muchos dicen que la raza humana no ha sido la especie que más ha habitado la tierra y que fueron los dinosaurios quienes ostentan dicho primer puesto; sin embargo, tal afirmación no es del todo cierta si tomamos en consideración que es la naturaleza, los organismos vivos y todos los componentes que la integran quienes han sido la presencia viviente que ha reinado la tierra desde los tiempos más remotos; es más, ella misma ha sido quien ha propiciado la creación y nacimiento de todas las formas de vida que hoy existen y que han existido, entre ellas, la raza humana que solo ocupa un mínimo extremo de tiempo en el calendario cósmico.

Por otra parte, tampoco es cierta la afirmación - extremista- de que el hombre destruirá el medio ambiente y a la naturaleza, hasta el punto en que no va a ser viable la resiliencia de la biosfera y los recursos; no, la especie humana está en capacidad de destruir y contaminar el medio y la naturaleza hasta el punto de que sea la raza humana quien no podrá subsistir, y luego, extinta nuestra raza, la naturaleza podrá comenzar un largo periodo de restauración, pues mientras el planeta tenga las condiciones propicias para albergar vida, la naturaleza podrá seguir subsistiendo aun después de extinta nuestra raza; en consecuencia, el antropocentrismo visto como la doctrina que posiciona al hombre en el centro de todo el orden de cosas del universo, como fin absoluto de la naturaleza y punto de referencia de todas las cosas, puede ser claramente la doctrina que nos explica y nos enseña que si no cuidamos el ambiente, estamos acabando y condenando nuestra especie, bajo el nuevo entendimiento que se propone en este escrito.

Si bien se reconoce que el antropocentrismo es una corriente filosófica limitada, al ubicar en el centro del cosmos al hombre, impartiendo cierta superioridad con las demás formas de vida en nuestra tierra, desde un punto de vista jurídico dicho principio puede ser reformulado sobre la base de que el derecho en sí mismo se encarga de regular el comportamiento humano para tratar de garantizar el valor de justicia y establecer un orden social que haga posible la convivencia de los hombres, centrando su discurso en la dignidad humana, dignidad que solo podrá ser entendida y garantizada en condiciones de salubridad ambiental que no afecten la salud ni la vida del hombre; en tal sentido, el antropocentrismo recobra desde lo jurídico una importancia conceptual que se aleja de ser una corriente que implique la destrucción del medio ambiente, pues lo que pretende es que las condiciones medio ambientales dejen albergar la vida humana y la supervivencia de la especie en condiciones dignas, situación que es jurídicamente lo primordial para el derecho.

Ahora bien, la Corte Constitucional como lo vimos anteriormente ha hecho un rechazo expreso a la corriente antropocéntrica, no obstante, en algunos de sus pronunciamientos (en particular uno de los más importantes), sustenta de manera tácita lo que se expresa en el presente escrito con la siguiente afirmación: 
...Es a partir del ser humano, su dignidad, su personalidad jurídica y su desarrollo (artículos $1^{\circ}, 14$ y 16 de la Constitución), que adquieren sentido los derechos, garantías y los deberes, la organización y funcionamiento de las ramas y poderes públicos. 1 así como la defensa del ambiente, en tanto que éste es el entorno vital del hombre ${ }^{16}$.

La sentencia citada claramente parte de una premisa antropocéntrica, pues edifica su argumento de que de la condición humana es de donde emanan los derechos y garantías que se transcriben en la Constitución, como por ejemplo el ambiente sano, el cual debe ser resguardado en condiciones favorables por ser el entorno vital para el hombre; como comentario al margen, es importante resaltar que dicha transcripción tiene como fuente uno de los pronunciamientos más importantes para el derecho constitucional ambiental, como lo es la sentencia que acuñó el término de constitución ecológica, que a su vez también desarrolla y sustenta por qué nuestro ordenamiento superior mereció tal calificativo ${ }^{17}$. En otrora, la misma corporación, esta vez en un pronunciamiento de constitucionalidad, cita el principio 1 de la declaración de Río de Janeiro - transcrito ut supra- como la fuente principal de la obligación constitucional de una utilización racional de recursos naturales ${ }^{18}$, argumentos que nos invitan a reformular el principio del antropocentrismo ambiental, a luz no solo de las declaraciones internacionales citadas sino de nuestro mismo ordenamiento constitucional, que además de ser una constitución ecológica, es principalmente una "constitución humana".

\section{CONCLUSIÓN}

En conclusión, bajo este análisis, el principio del antropocentrismo ambiental deriva del principio y derecho a la dignidad humana, toda vez que reiteramos, la visión antropocentrista no debe ser confundida con la sobre explotación irresponsable de recursos naturales, entendimiento que aunque puede ser limitado al considerar al hombre como el centro del cosmos, por lo menos desde un enfoque jurídico cobra cierta importancia toda vez que nuestro ordenamiento constitucional $-\mathrm{y}$ la mayoría en el mundo- se encuentran fundados con el objetivo principal de garantizar los derechos humanos, que para el caso en concreto nos referíamos al derecho a gozar de un ambiente sano, que de no garantizarse puede resultar en la vulneración de los derechos a la vida, a la salud, a la dignidad humana, al libre desarrollo de la personalidad, entre otros; sobre este tema, recordemos la afirmación hecha por la

16 Corte Constitucional, Sentencia T 411 de 1992, M.P.: Alejandro Martínez Caballero.

17 Corte Constitucional, Sentencia T 411 de 1992, M.P.: Alejandro Martínez Caballero.

18 “...ya que los 'seres humanos constituyen el centro de las preocupaciones relacionadas con el desarrollo sostenible' (Principio 1 de la Declaración de Río sobre el medio ambiente y el desarrollo). Por eso, el mandato constitucional obliga es a efectuar una utilización sostenible de tales recursos" (Corte Constitucional, Sentencia C 058 de 1994, M.P.: Alejandro Martínez Caballero. 
Corte Constitucional en una providencia al decir que: "El derecho al medio ambiente no se puede desligar del derecho a la vida y a la salud de las personas" 19 . Teniendo en cuenta dicho argumento, el principio del antropocentrismo debe reformularse como la conservación y preservación de ecosistemas donde el hombre pueda vivir dignamente; de hecho, son varios los pronunciamientos de la Corte Constitucional que se relacionan la vida y dignidad humana con el derecho a gozar de un ambiente sano bajo la figura de la conexidad de derechos y los derechos fundamentales.

Desde luego, quienes no compartan dicho entendimiento deben, por lo menos, reconocer que dicho principio se encuentra inmerso en nuestro ordenamiento, como lo hemos visto en las declaraciones de principios mencionadas; por consiguiente, en aras de proteger nuestros recursos naturales debemos procurar que la interpretación de dicho principio no sea egoísta y mal intencionada, y que por el contrario, se encuentre en armonía con nuestra constitución ecológica.

La conexidad y cercanía entre el derecho a gozar de un ambiente sano con los derechos a la vida y la dignidad humana, así como el impulso jurisprudencial que viene tratando de reconocer al derecho a gozar de un ambiente sano como un derecho fundamental ${ }^{20}$, es lo que se considera que es el principio del antropocentrismo ambiental, pues es la humanización y personificación del derecho colectivo-ambiente sano-hacia la garantización de la dignidad humana; tal acepción, desvirtúa el sofisma y la mala interpretación del antropocentrismo como una excusa irresponsable de agotamiento de recursos naturales en virtud del "bienestar humano".

Por ello, con motivo y ocasión del presente escrito, exhortamos a todos los lectores a reformular el entendimiento que hasta el momento viene dándose a la corriente antropocentrista, la cual consideramos que ha sido mal interpretada en mayor parte por quienes sobreponen su bienestar particular y económico antes que el bienestar general y del medio ambiente; así las cosas, ponemos de presente una interpretación de la corriente antropocentrista evolucionada y a la luz de nuestro ordenamiento constitucional, que incorpora los avances jurídico-políticos mundiales contemporáneos como lo es el aterrizaje del antropocentrismo en el principio de la dignidad humana y el de desarrollo sostenible, así como también la tesis de nuestra reformulación, la cual se sustenta en que dicho principio pretende no solo el bienestar particular sino la supervivencia de la especie humana y el disfrute del derecho a la vida.

\section{REFERENCIAS}

Corte Constitucional de Colombia. Sentencia T 411 de 1992, M.P.: Alejandro Martínez Caballero.

Corte Constitucional de Colombia. Sentencia T 092 de 1993, M.P.: Simón Rodríguez Rodríguez.

19 Corte Constitucional, Sentencia T 092 de 1993, M.P.: Simón Rodríguez Rodríguez.

20 Corte Constitucional, Sentencia C 632 de 2011, M.P.: Gabriel Eduardo Mendoza Martelo. 
Corte Constitucional de Colombia. Sentencia C-528 de 1994, M.P.: Fabio Morón Díaz.

Corte Constitucional de Colombia. Sentencia C 058 de 1994, M.P.: Alejandro Martínez Caballero.

Corte Constitucional de Colombia. Sentencia T 724 de 2001, M.P.: Nilson Pinilla Pinilla.

Corte Constitucional de Colombia. Sentencia C-339 de 2002, M.P.: Jaime Araujo Rentería.

Corte Constitucional de Colombia. Sentencia C-818/05, M.P.: Rodrigo Escobar Gil

Corte Constitucional de Colombia. Sentencia C-818/05, M.P.: Rodrigo Escobar Gil.

Corte Constitucional de Colombia. Sentencia C-257 de 2008, M.P.: Clara Inés Vargas.

Corte Constitucional de Colombia. Sentencia T 129 de 2011, M.P.: Jorge Iván Palacio Palacio.

Corte Constitucional de Colombia. Sentencia T 608 de 2011, M.P.: Juan Carlos Henao Pérez.

Corte Constitucional de Colombia. Sentencia C 632 de 2011, M.P.: Gabriel Eduardo Mendoza Martelo.

Declaración de Río de Janeiro de junio de 1992 sobre Medio Ambiente y Desarrollo. Ley 84 de 1989

Lorenzetti, R. L. (s.f.). Teoría del derecho ambiental (p. 63).

Molina, J (2014). Derechos de la naturaleza, historia y tendencia actuales.

Roa, J. A. (2014). Derechos de la naturaleza, historia y tendencias actuales.

Santofimio, J. O. (s.f.). Tratado de derecho administrativo (t.I, p. 441). 